\title{
Two-step Procedure for Early Neonatal Surgery of Fetal Hydrocephalus
}

\author{
Kazuyoshi MORIMOTO*,**, Toru HAYAKAWA*, Toshiki YOSHIMINE*, \\ Akatsuki WAKAYAMA** and Ryotaro KURODA*** \\ *Department of Neurosurgery, Osaka University Medical School, Osaka; **Department \\ of Neurosurgery, Osaka Medical Center and Research Institute for Maternal \\ and Child Health, Izumi, Osaka; ${ }^{* * *}$ Department of Neurosurgery, \\ Kinki University School of Medicine, Osaka-sayama, Osaka
}

\begin{abstract}
This retrospective study analyzed the diagnosis and treatment of 36 infants with central nervous system anomalies diagnosed antenatally by ultrasonographic studies between December, 1987 and December, 1990. Magnetic resonance imaging of the fetuses without maternal or fetal sedation/ anesthesia was very useful, as the fetal ventricular system was depicted clearly. Twenty-three infants with hydrocephalus underwent early postnatal surgical emplacement of a miniature Ommaya's reservoir. Continuous cerebrospinal fluid aspiration was combined with intracranial pressure monitoring. Observation of the ventricular size used ultrasonography through the anterior fontanelle. This technique controlled the intracranial pressure during the early neonatal period without serious complications. A ventriculoperitoneal shunt was emplaced 1 month later as the second, more permanent treatment. This two-step procedure achieves brain reconstitution and prevents irreversible neurological damages. Clinical and radiographic findings are presented to illustrate the effectiveness of this approach.
\end{abstract}

Key words: hydrocephalus, magnetic resonance imaging, neonatal surgery, prenatal diagnosis, ultrasonography

\section{Introduction}

Experience shows that delay in surgical management of hydrocephalus generally results in greater impairment of intelligence and intracranial structural damage. ${ }^{21,32)}$ Accordingly, surgical intervention for fetal central nervous system (CNS) anomalies is carried out as early in life as medically feasible. However, the therapeutic value of prenatal surgical procedures such as ventriculoamniotic shunt placement is still uncertain. ${ }^{5.15)}$

Although recent advances in diagnostic procedures allow early visualization of CNS anomalies, the timing of therapeutic intervention remains controversial. ${ }^{26)}$ Early antenatal diagnosis and postnatal ex utero treatment remains the preferred obstetric and pediatric practice. Magnetic resonance (MR) imaging is the most useful method for antenatal diag-

Received May 27, 1992; Accepted August 27, 1992 nosis of CNS anomalies. ${ }^{10)}$ Until recently, however, in utero MR imaging of the fetus was limited by fetal mobility. ${ }^{19)}$ We have solved this problem by induction of spontaneous sleep in the fetus which allows optimum MR imaging without maternal or fetal sedation/anesthesia.

Here, we present a retrospective analysis of the clinical features, surgical treatment, and outcome of 36 infants treated for hydrocephalus, and our guidelines for antenatal MR imaging to identify fetal CNS anomalies and early postnatal two-step surgical management.

\section{Patients and Methods}

Thirty-six infants with CNS anomalies receiving treatment at the Departments of Neurosurgery, Osaka University Medical School and Osaka Medical Center and Research Institute for Maternal and Child Health between December, 1987 and 
Table 1 Factors used for logistic regression analysis

Gestational age at detection

Gestational age at delivery

Antenatal ultrasound and $\mathrm{MR}$ imaging findings ratio of ventricular to hemispheric size biparietal diameter

Postnatal neuroradiographic findings cerebroventricular index head circumference

Obstetrical management vaginal delivery Caesarean delivery

Postnatal surgical management surgery performed no surgery

December, 1990 were analyzed using the clinical features listed in Table 1.

All computations were performed by the commonly used STAX statistical software (software running in STAX written by the Tokyo University Medical School, Tokyo).

The data are expressed as mean \pm SD. The paired Student's t-test was used to assess the significant differences in mean values before and after surgical treatment for the same patients $(n=20)$. The unpaired Student's t-test was used to compare data between two groups. A p value less than 0.01 was taken as statistically significant.

\section{Results}

\section{Clinical features}

The gestational age when prenatal ultrasonographic evaluation detected the CNS anomalies ranged from 17 to 40 weeks (mean, $31.0 \pm 4.2$ wks) (Fig. 1 left). The age of the fetus at delivery ranged from 23 to 40 weeks (mean, $35.6 \pm 3.4$ wks) (Fig. 1 right).

The patients were divided into two groups, those having postnatal surgery $(n=24)$ and those without $(n=12)$. Any surgical intervention, whether placement of a miniature Ommaya's reservoir, ${ }^{24)}$ shunting procedure for hydrocephalus, or closure of myelomeningocele, was regarded as surgical management. The weight at birth was similar with the surgical group ranging from 996 to $3770 \mathrm{gm}$ (mean, $2538 \pm 644 \mathrm{gm})$ and the nonsurgical group ranging from 574 to $3269 \mathrm{gm}$ (mean, $2413 \pm 831 \mathrm{gm}$ ). Sixteen of 24 infants in the surgical group were delivered by Caesarean section, in contrast to only two of 12 infants in the nonsurgical group.

\section{Diagnostic procedures}

Maternal computed tomographic (CT) scan was performed in the seven initial patients of this series. However, in the 24 most recent patients, MR imaging was used. The other five cases were diagnosed by ultrasonography alone.

Table 2 shows primary diagnosis of 36 fetuses.
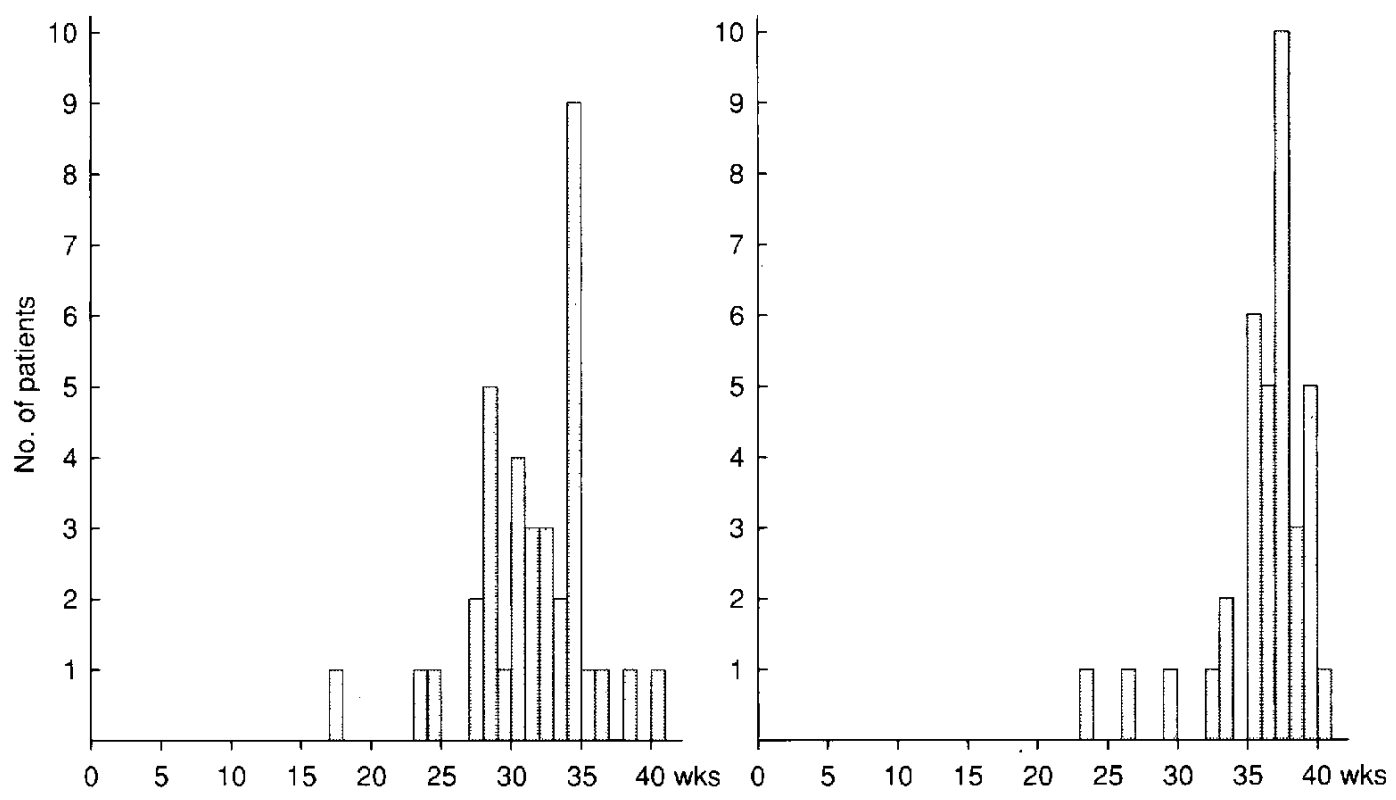

Fig. 1 Gestational ages at detection of fetal CNS anomalies (left) and at delivery (right). 
Table 2 Primary diagnosis of 36 fetuses with CNS anomalies

\begin{tabular}{lc} 
Hydrocephalus & 11 \\
Encephalomeningocele & 5 \\
Hydranencephaly & 2 \\
Arachnoid cyst & 2 \\
$\begin{array}{l}\text { Dandy-Walker malformation } \\
\text { Neoplasm }\end{array}$ & 2 \\
$\begin{array}{l}\text { Hydrocephalus associated with anomalies } \\
\text { myelomeningocele } \\
\text { cloverleaf head } \\
\text { single ventricle of heart }\end{array}$ & $1^{*}$ \\
\multicolumn{1}{c}{ Total } & 11 \\
\end{tabular}

*Verified as a teratoma at autopsy.

Hydrocephalus in two fetuses improved spontaneously with reduced ventricular size throughout the third trimester of gestation. However, fetal ventriculomegaly usually evolved into progressive hydrocephalus and required surgical intervention. The etiology was uncertain in most cases. No cytogenetic abnormalities or infectious agents such as Toxoplasma, rubella, cytomegalovirus, and herpes simplex virus were identified. There was one infant with a family history of X-linked hydrocephalus.

Maternal MR imaging was performed without sedation/anesthesia. Natural sleep was induced in fetuses by maternal walking with physical exercise prior to the MR imaging procedures. MR images were obtained using a 1.5-Tesla magnet which clearly demonstrated the fetal ventricular system containing fluid isodense with cerebrospinal fluid (CSF) affecting the neighboring neural structures (Fig. 2). Evaluation of the fetal spine in utero was very difficult except in a few cases. Figure 3 shows the best ultrasonographic scans of the abnormal widening and opening of the posterior element in the spine of a
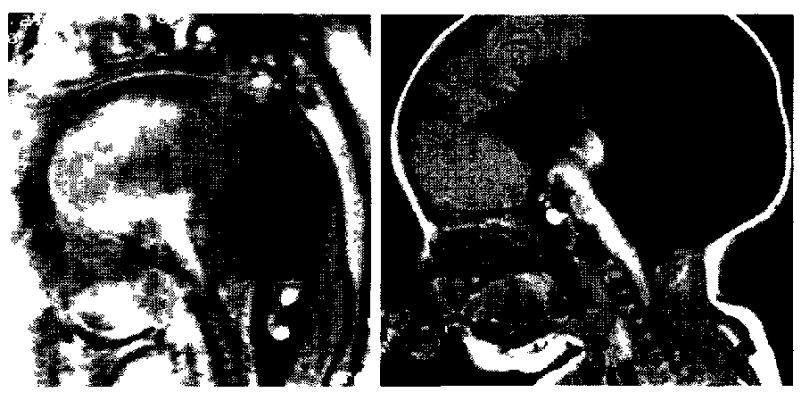

Fig. 2 Prenatal maternal (left) and neonatal MR images (right), sagittal views, of a patient with Dandy-Walker malformation and a large posterior fossa cyst.

fetus with myelomeningocele.

Figure 4 shows measurements of the lateral ventricular width/hemispheric width ratio on the prenatal ultrasonographic scan, and the cerebroventricular index defined as the maximal width of the lateral ventricle/hemispheric width on the postnatal CT scan. These two values were significantly correlated (Fig. 5 upper). The head circumference at birth and the biparietal diameter on the prenatal ultrasonographic scan were also correlated significantly (Fig. 5 lower).

\section{Surgical treatment}

Twenty-four infants were treated surgically during the early neonatal period (Table 3). The initial surgical procedure for hydrocephalus during the early neonatal period consisted of a stump drainage system with a miniature Ommaya's reservoir (Fuji Systems, Tokyo) (Fig. 6) ${ }^{24,30)}$ designed especially for neonates and premature infants. The dome is $5 \mathrm{~mm}$ thick and the ventricular catheter $3 \mathrm{~cm}$ long. The catheter was placed in the lateral ventricle under ultrasonographic guidance at the right corner of the
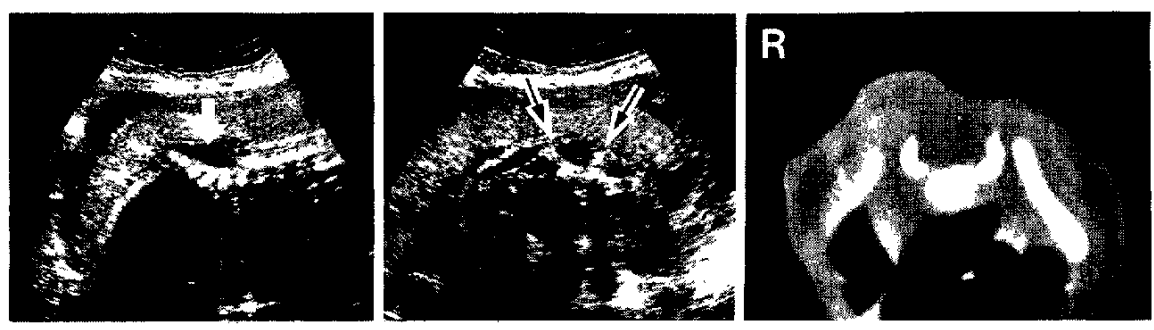

Fig. 3 Sacral myelomeningocele in a 28-week fetus. left: Parasagittal ultrasonographic scan, showing the meningeal sac with low echogenicity (arrow). center: Transverse ultrasonographic scan, showing opening of the posterior elements (arrows). right: Postnatal spinal CT scan corresponding to the fetus in the center figure. 


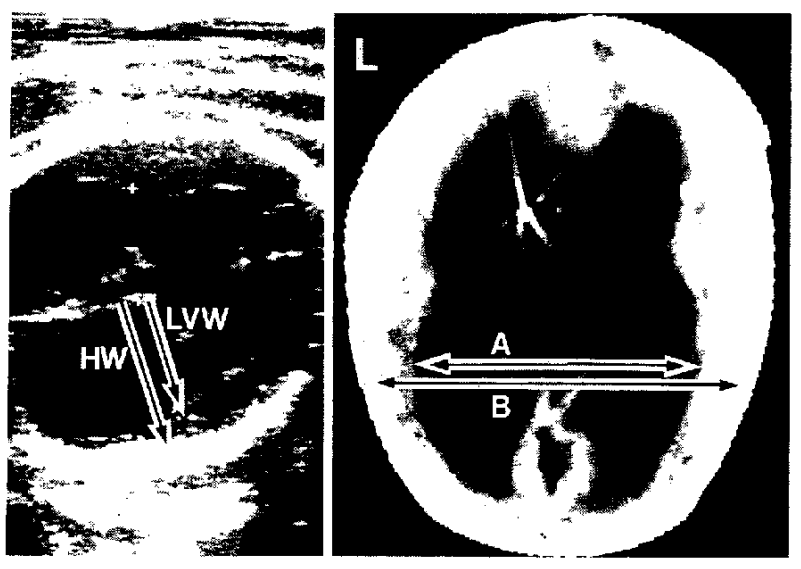

Fig. 4 Measurements of the lateral ventricular width/ hemispheric width $(\mathrm{LVW} / \mathrm{HW})$ ratio on the prenatal ultrasonographic scan (left), and the cerebroventricular index (CVI) as the maximal width of the lateral ventricle (A)/hemispheric width (B) on the postnatal CT scan.
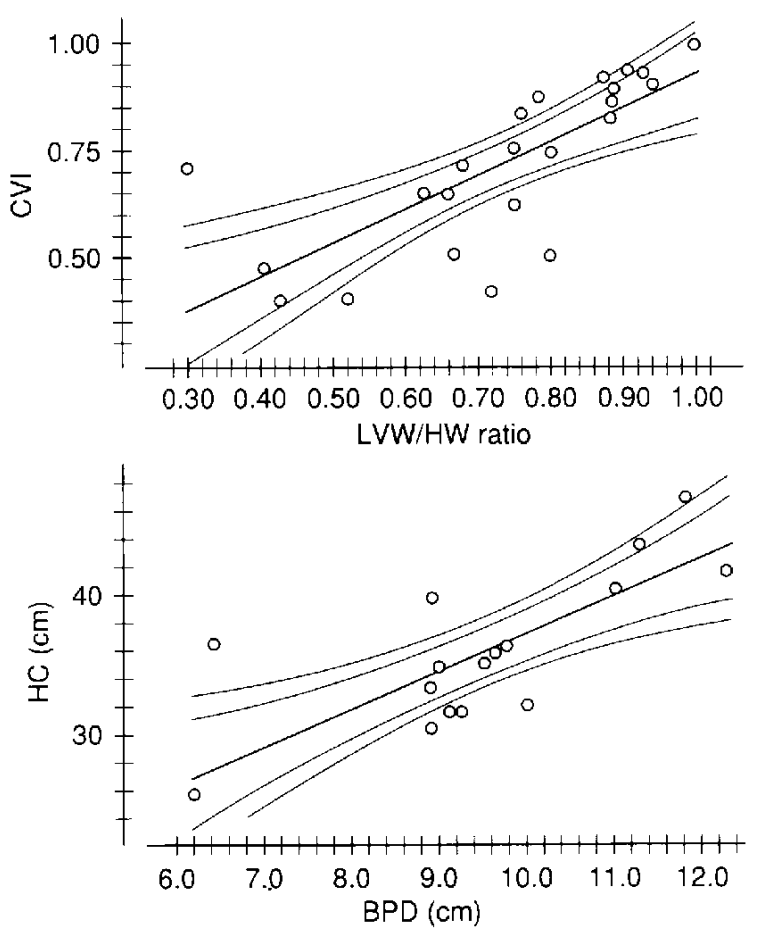

Fig. 5 upper: The LVW/HW ratio and the CVI. there is a significant correlation ( $\mathrm{Y}=0.15312+$ $0.774506 \mathrm{X}, \mathrm{r}=0.730919$ ). lower: The head circumference (HC) at birth and the fetal biparietal diameter (BPD). There is a statistically significant correlation $(\mathrm{Y}=10.7948+$ 2.66256X, $\mathrm{r}=0.774956)$.
Table 3 Early neonatal surgical procedure for 24 infants

\begin{tabular}{lr} 
Miniature Ommaya's reservoir placement & 23 \\
VP shunt & 20 \\
Cystperitoneal shunt & 2 \\
Repair of myelomeningocele & 11 \\
Repair of encephalomeningocele & 4 \\
\hline & 60 \\
\hline
\end{tabular}

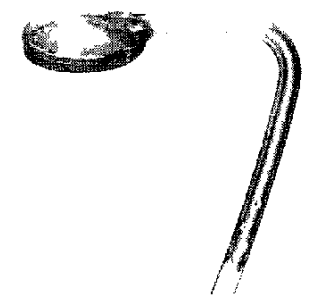

$$
|||||+||||||||||||||||||||||||+|||||||+||||+|||||||||||||| \mid
$$

Fig. 6 Miniature Ommaya's reservoir. Scale in $\mathrm{cm}$.

anterior fontanelle or the asterion. The procedure did not cause bleeding or tissue damage. After surgery, a 27-gauge scalp vein needle was inserted percutaneously into the reservoir and the CSF aspirated continuously with an automatic apparatus for exchange transfusion (Atom Co., Tokyo) with modified Chan's prolonged therapeutic external ventricular drainage (Fig. 7). ${ }^{1,2,8,33)}$ The aspiration rate of surplus CSF was from 0.5 to $2 \mathrm{ml} / \mathrm{hr}$ during the first month. The loss of electrolytes and water was replenished. There was no incidence of severe ventricular infection. Chronic catheter patency was excellent except in one case requiring a revision because of blockage of the ventricular catheter. The second surgical procedure 1 month later included the ventriculoperitoneal (VP) shunt procedure with a lowpressure Silastic shunt device (type 3; Dow Corning Co., Kanagawa) in 20 patients. Repair of myelomeningocele and encephalomeningocele was carried out in 11 and four patients, respectively, at the second surgical procedure.

\section{Serial measurement of intracranial pressure (ICP)}

Using a sterile technique, a 27-gauge scalp vein needle was inserted percutaneously into the miniature 
fiberoptic pressure transducer

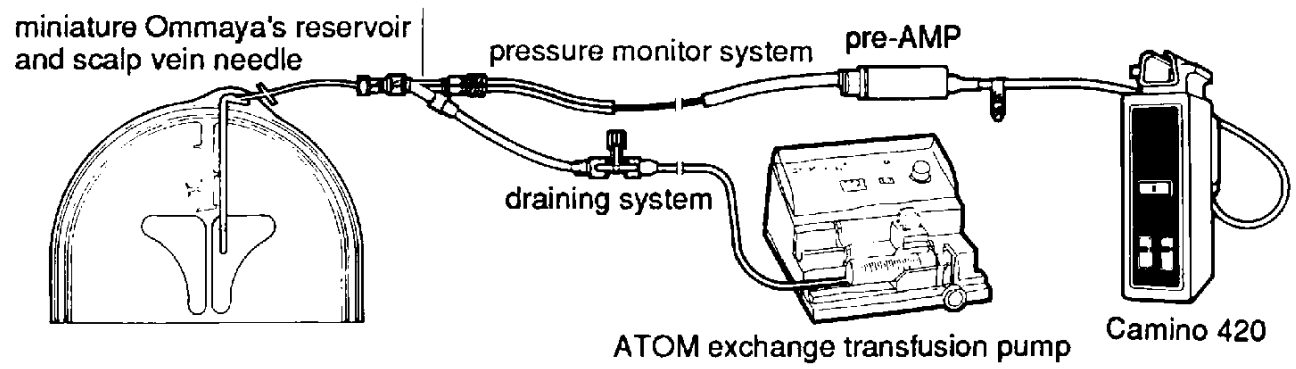

Fig. 7 Diagram, showing the arrangement of CSF drainage and the ICP monitor used in this study. Continuous drainage via a miniature Ommaya's reservoir by an automatic aspiration apparatus for exchange transfusion and fiberoptic ICP monitoring. Reprinted with permission from Morimoto et al., Shoni No Noshinkei 17: 89-94, 1992.

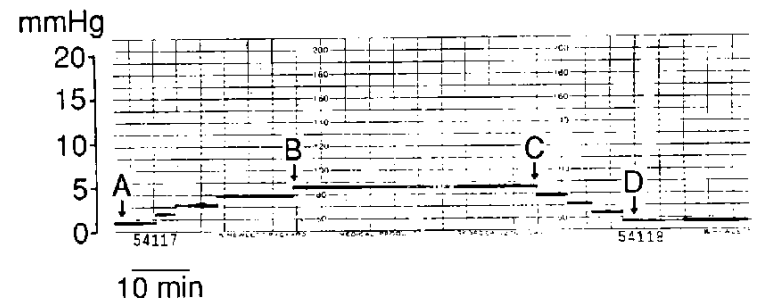

Fig. 8 Ventricular pressure tracing recorded from a miniature Ommaya's reservoir calibrated at the level of the external ear. Note increase in pressure (A to B) and plateau (B to C) after locking of the CSF drainage system. Release was followed by return to the initial pressure level (C to D).

Ommaya's reservoir and connected to a fiberoptic pressure monitor (Digital Pressure Monitor, Model 420; Camino Laboratories, San Diego, Cal., U.S.A.) with the transducer at the tip. The mean pressure was displayed digitally while the ICP was monitored using a graphic recorder (Neonatal Graphic Recorder, Model 78834A, 8232B; Hewlett-Packard $\mathrm{GmbH}$, Boblingen, Germany) calibrated with the pressure at the level of the external ear as reference. The intraventricular pressure was measured by locking the drainage system, which resulted in an increase in pressure and a plateau. Release of the lock was followed by return of the pressure to the initial level (Fig. 8).

\section{Outcome}

The follow-up period ranged from 1 to 40 months (mean, $15.7 \pm 10.6 \mathrm{mos}$ ). There was one death among 24 surgically treated patients. This infant had the most severe hydrocephalus with myelomenin- gocele and kyphosis. He died of pulmonary complication and hypoxic encephalopathy 1.5 months after birth. In all other surgical cases, there was at least some clinical improvement. Ventriculomegaly improved more promptly and markedly after the VP shunting procedure. The hydrocephalus eventually resolved and re-expansion of the brain occurred in 12 patients. Figure 9 shows serial ultrasonographic scans of a representative infant with hydrocephalus. The cerebroventricular index on the postnatal examination ranged from 0.41 to 0.92 (mean, $0.71 \pm$ 0.22 ) before the VP shunting procedure and from 0.29 to 0.54 (mean, $0.41 \pm 0.01$ ) afterwards ( $\mathrm{p}<$ $0.01, \mathrm{n}=20$ ).

\section{Discussion}

With the increasing availability of obstetric ultrasonography in the past decade, more fetal CNS abnormalities have been detected in utero. ${ }^{4,9,11,12,23,26,27)}$ The introduction of MR imaging during pregnancy has provided more accurate assessment of a variety of fetal abnormalities. ${ }^{10,18,22)}$ Because MR imaging requires a comparatively long imaging time, the images are degraded by fetal motion. Reduction of such artifacts can be achieved by maternal and fetal sedation/anesthesia, but MR imaging can be more easily achieved when the fetus is larger and relatively less mobile in the third trimester of pregnancy. Maternal walking prior to the MR imaging procedure can also induce natural sleep in the fetus and eliminate motion artifacts. $T_{1}$-weighted spin-echo $M R$ images demonstrate the fetal brain as intermediate intensity and CSF as a low-intensity signal. MR imaging is therefore particularly suitable for detection of fetal CSF accumulation and abnormalities of the intracranial structure (Fig. 2 left, Fig. 9 upper). MR im- 


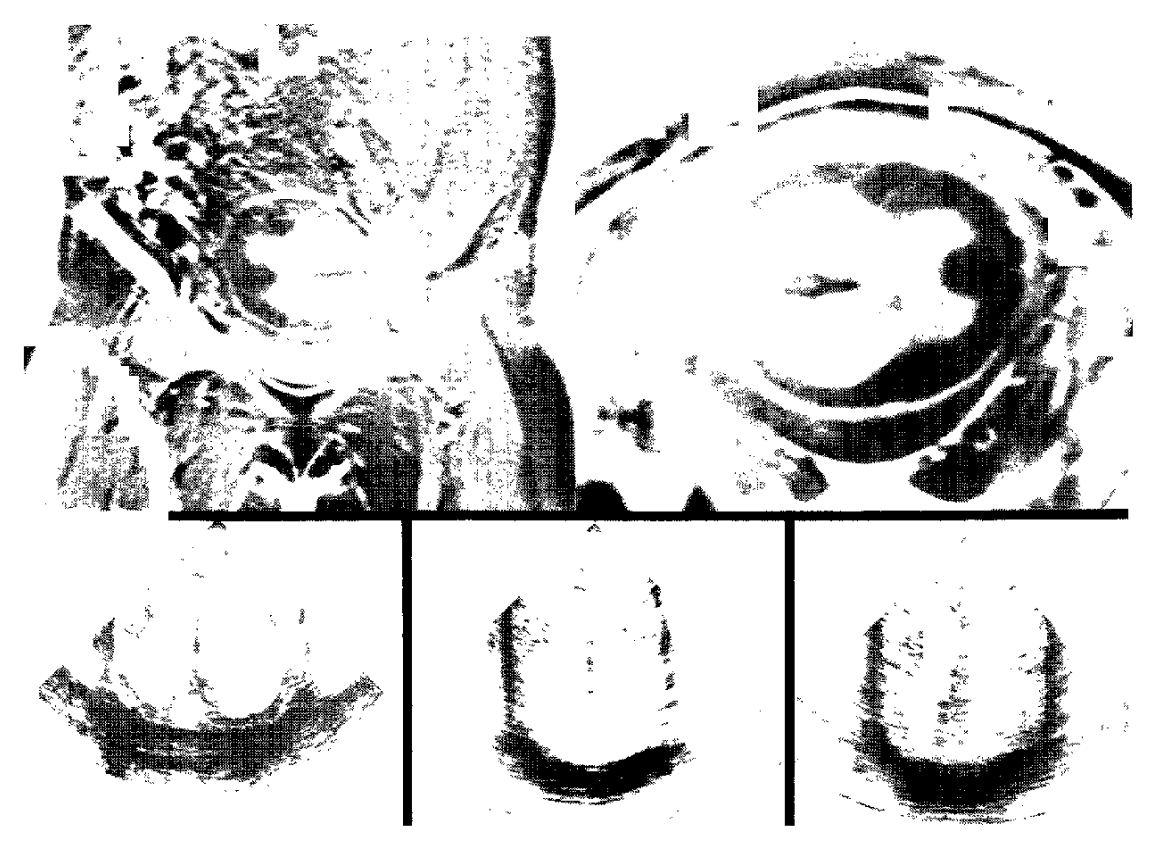

Fig. 9 upper: Prenatal maternal MR images of a patient with hydrocephalus at 34 weeks of gestation. lower: Serial postnatal ultrasonograms after neonatal surgical intervention. Sonograms were obtained immediately after birth (left), after placement of a miniature Ommaya's reservoir (center), and after VP shunting (right). Reprinted with permission from Kubo et al., Shoni No Noshinkei 15: $311-315,1990$.

aging is therefore the method of choice to determine the surgical intervention for fetal CNS anomalies.

Since Clewell et $a l^{5)}$ first reported the ventriculoamniotic shunting procedure in 1982, the management of fetal CNS anomalies has been controversial among obstetricians, neonatologists, pediatric neurologists, and neurosurgeons. . $^{6,13,16,29)}$ However, early diagnosis and surgical correction offer a good chance of complete brain reconstitution and thus good surgical results. Del Bigio et al. ${ }^{7)}$ documented periventricular pathology in a neonate with fetal hydrocephalus, where the ependyma was denuded and replaced with glial cell processes but there was no obvious axonal pathology. Oi et al. ${ }^{25}$ analyzed 20 infants with fetal hydrocephalus, showing that the only significant factor affecting the prognosis of intrauterine hydrocephalus was the intrauterine period after diagnosis. The International Fetal Surgery Registry reported 34 catheter shunt procedures for fetal hydrocephalus in 1986, with $10.3 \%$ mortality related to the procedure and $52.9 \%$ morbidity with serious neurological handicaps among survivors. ${ }^{15)}$ Hence the early trials of surgical treatment of fetal hydrocephalus did not show reduced morbidity among survivors. Chervenak et al. ${ }^{3)}$ reviewed 53 consecutive cases of fetal hydrocephalus in- cluding 14 cases $(26 \%)$ with ventriculoamniotic shunt placement in utero but did not establish the efficacy of the procedure. It is possible that neurosurgical intervention in the fetal stage lengthens the survival time without improving the outcome.

Lober $^{14]}$ recommended ventriculocardiac shunt during the first week of life for hydrocephalic infants. He obtained an improvement in survival $(75 \%)$ and normal intellectual development $(80 \%)$ after performing shunt operations in the neonatal period. His results suggested that early surgical intervention during the neonatal period can improve brain function and delay in treatment during the neonatal period is the most detrimental factor leading to a poor prognosis. This procedure requires further evaluation by a prospective study of ex utero management at term or after early induction of delivery.

The ICP during the neonatal period is normally very low, but rises later to the level seen in adult life. The ICP among newborn infants is reported to be $10-14 \mathrm{mmH}_{2} \mathrm{O}$, but rises to $45 \pm 12$ (SD) $\mathrm{mmH}_{2} \mathrm{O}$ at 10 or more days after birth. ${ }^{31)}$ Newborn infants usually lose weight in association with salt and water loss during the first few days of life. During this peri- 
od, subatmospheric ICP is common. The ICP at different stages of infancy should be taken into consideration in postnatal management of fetal hydrocephalus. ${ }^{28)}$ For this reason, we prefer early two-step surgical management with continuous CSF aspiration through a miniature Ommaya's reservoir as the first step and the VP shunt procedure 1 month later as the second step of treatment. ${ }^{16,17,20,30)}$

Counseling and communication with parents about the accurate prognosis for fetal CNS anomalies are important. Normal development in treated fetuses is expected to be $35-66 \%$ as compared to $19.5 \%$ in untreated fetuses. ${ }^{16)}$ This prognosis is still less than satisfactory even after surgical intervention. The outcome is also determined by a combination of factors including perinatal damage during delivery, apnea, and unrecognized seizures that may lead to hypoventilation, hypoxia, and acidosis. Therefore, the medical team should consist of obstetricians, neonatologists, pediatric neurologists, and pediatric neurosurgeons equipped with a perinatal intensive care facility to achieve a successful outcome.

\section{Acknowledgments}

We greatly appreciate Prof. Takehiko Yanagihara of Mayo Clinic, Rochester, Minn., U.S.A. for his helpful review, Dr. Noriyuki Suehara of Department of Obstetric, Osaka Medical Center and Research Institute for Maternal and Child Health and Dr. Tetsu Takagi of Department of Obstetric and Gynecology, Osaka University Medical School for their guidance, and Ms. Kyouko Kousaka for meticulous preparation of this manuscript.

This study was supported in part by an Elleair grant from Nihon Jido Katei Bunka Kyokai, Sukoyaka grant from Osaka Koshu Eisei Kyokai, and Marumo grant from Japanese Association for Acute Medicine.

\section{References}

1) Abott R, Epstein FJ, Wisoff JH: Chronic headache associated with a functioning shunt: Usefulness of pressure monitoring. Neurosurgery 28: 72-77, 1991

2) Chan KH, Mann KS: Prolonged therapeutic external ventricular drainage: A prospective study. Neurosurgery 23: 436-438, 1988

3) Chervenak FA, Berkowitz BL, Tortora M, Hobbins JC: The management of fetal hydrocephalus. Am J Obstet Gynecol 151: 933-942, 1985

4) Chervenak FA, Duncan C, Ment LR: Perinatal management of meningomyelocele. Obstet Gynecol 63: $376-380,1984$
5) Clewell WH, Johnson ML, Meier PR: A surgical approach to the treatment of fetal hydrocephalus. $N$ Engl J Med 306: 1320-1325, 1982

6) Cochrane DD, Myles T: Management of intrauterine hydrocephalus. J Neurosurg 57: 590-596, 1982

7) Del Bigio MR, Bruni JE, Fewer HD: Human neonatal hydrocephalus: An electron microscopic study of the periventricular tissue. $J$ Neurosurg 63 : $56-63,1985$

8) Funato $M$, Shimada $S$, Tamai H, Taki H, Yoshioka Y: Automated exchanged transfusion and exchange rate. Acta Paediatr Jpn 31: 572-577, 1989

9) Hill LM, Breckle R, Gehrking WC: The prenatal detection of congenital malformations by ultrasonography. Mayo Clin Proc 58: 805-826, 1983

10) Hill MC, Lande IM, Larsen JW: Prenatal diagnosis of fetal anomalies using ultrasound and MRI. Recent Advances in Practical Pediatric Radiology 26: 287307,1988

11) Holzgreve W, Ming P: Genetic aspects of fetal disease. Semin Perinatol 13: 260-277, 1989

12) Johnson ML, Dunne MG, Mack LA, Rashbaum CL: Evaluation of fetal intracranial anatomy by static and real-time ultrasound. $I$ Clin Ultrasound 8: $311-$ 318,1980

13) Levene MI, Bennett MJ, Punt J: Fetal and Neonatal Neurology and Neurosurgery. Edinburgh, Churchill Livingstone, $1988,575 \mathrm{pp}$

14) Lober J: Ventriculo-cardiac shunts in the first week of life: Results of controlled trial in the treatment of hydrocephalus in infants born with spina bifida cystica or cranium bifidum. Develop Med Child Neurol 20: 13-22, 1969

15) Manning FA, Harrison MR, Rodeck C: Catheter shunts of fetal hydronephrosis and hydrocephalus. Report of the International Fetal Surgery Registry. $N$ Engl J Med 315: 336-340, 1986

16) Manwaring KH: Neurosurgery of the fetus, in Wilkins RH, Rengachary SS (eds): Neurosurgery Update II. New York, McGraw-Hill, 1990, pp 292-297

17) Marlin AE: Protection of the cortical mantle in premature infants with posthemorrhagic hydrocephalus. Neurosurgery 7: 464-468, 1980

18) Mattison DR, Angtuaco T: Magnetic resonance imaging in prenatal diagnosis. Clin Obstet Gynecol 31: 353-389, 1988

19) McCarthy SM, Filly RA, Stark DD: Obstetrical magnetic resonance imaging: Fetal anatomy. Radiology 154: 427-432, 1985

20) McComb JG, Ramos AD, Platzker ACG, Henderson DJ, Segall HD: Management of hydrocephalus secondary to intraventricular hemorrhage in the preterm infant with subcutaneous ventricular reservoir. Neurosurgery 13: 295-300, 1983

21) McCullough DC, Balzer-Martin LA: Current prognosis in overt neonatal hydrocephalus. $J$ Neurosurg 57: 378-383, 1982

22) McRobbie D, Foster MA: Pulsed magnetic field exposure during pregnancy and implications for NMR 
fetal imaging: A study with mice. Magn Reson Imaging 3: 231-234, 1985

23) Michejda M, Hodgen GD: In utero diagnosis and treatment of non-human primate fetal skeletal anomalies. I. Hydrocephalus. JAMA 246; 10931097,1981

24) Morimoto K, Sumita T, Maeyama M, Mogami H: Extremely low-birth-weight infant with post-hemorrhagic hydrocephalus: Surgical procedure and recognition by sonography. No Shinkei Geka 13: 571-576, 1985 (in Japanese)

25) Oi S, Yamada H, Kimura M, Ehara K, Matsumoto S, Katayama K, Mochizuki M, Uetani Y, Nakamura $H$ : Factors affecting prognosis of intrauterine hydrocephalus diagnosed in the third trimester: Computerized data analysis on controversies in fetal surgery. Neurol Med Chir (Tokyo) 30: 456-461, 1990

26) Romero R, Pilu G, Jeanty P, Ghidini A, Hobbins JC: Prenatal Diagnosis of Congenital Anomalies. Norwalk, Appleton \& Lange, 1988, pp 1-79

27) Russ PD, Protorius DH, Manco-Johnson ML, Rumack CM: The fetal spine. Neuroradiology 28: 398-407, 1986

28) Shapiro K, Fried A, Marmarou A: Biomechanical and hydrodynamic characterization of the hydrocephalic infant. $J$ Neurosurg 63: 69-75, 1985
29) Vintzileos AM, Ingardia CJ, Nochimson DJ: Congenital hydrocephalus: A review and protocol for perinatal management. Obstet Gynecol 62: 539-549, 1983

30) Wakayama A, Morimoto $K$, Kitajima $H$, Ichiba $H$, Ebara H, Fujimura M, Suehara N, Hayakawa T: Extremely low birth-weight infant with hydrocephalus: Management of hydrocephalus using a miniature Ommaya's reservoir. No Shinkei Geka 19: 795-800, 1991 (in Japanese)

31) Welch $\mathrm{K}$ : The intracranial pressure in infants. $J$ Neurosurg 52: 693-699, 1980

32) Wilberger JE, Baghai P: Fetal neurosurgery. Neurosurgery 13: 596-600, 1983

33) Wood JH, Poplack DG, Flor WJ, Gunby EN, Ommaya AK: Chronic ventricular cerebrospinal fluid sampling, drug injections and pressure monitoring using subcutaneous reservoirs in monkeys. Neurosurgery 1: 132-135, 1977

Address reprint requests to: K. Morimoto, M.D., Department of Neurosurgery, Osaka Medical Center and Research Institute for Maternal and Child Health, 840 Murodo-cho, Izumi, Osaka 590-02, Japan. 